\title{
Aknede Deri Bakımı
}

\section{Doç Dr. Illknur Balta, ® Dr. Esra Kıratlı Nalbant}

Ankara Eğitim ve Araștırma Hastanesi, Deri ve Zührevi Hastalıklar Kliniği, Ankara, Türkiye

Öz

Akne; ergenlik döneminde sık görülen pilosebase birimin, kronik, enflamatuvar bir hastalığı olup, tedavisinde çok sayıda topikal ve sistemik ajan kullanılmaktadır. Bu tedavilerin yanı sıra, hastalara deri hijyenine ve bakımına yönelik önerilerde de bulunmak gerekir. Bu önerilerin hastaların tedaviye uyumunu artırdığı ve tedavi sonuçlarını iyileştirdiği gösterilmiştir. Bu nedenle akneli hastaların, akne lezyonlarını artırmadan ve tedaviye yardımcı olacak şekilde günlük deri bakımı konusunda bilgilendirilmesi ve kozmetik ürün seçimine yardımcı olunması oldukça önemlidir.

Anahtar Kelimeler: Akne, temizleme, nemlendirme

\section{Abstract}

Acne is a chronic inflammatory disease of the pilosebaceus unit, seen mostly in adolescence, and its treatment involves use of a variety of topical and systemic agents. Alongside these treatments, patients should also be provided with recommendations on skin hygiene and care. Such recommendations have been shown to increase patient adherence to treatment and to improve treatment outcomes. Therefore, it is important to inform acne patients about daily skin care to enhance treatment without increasing acne lesions and to help them choose appropriate cosmetic products.

Keywords: Acne, cleansing, moisturising

\section{Giriş}

Akne vulgarisde (AV) optimal tedavi; uygun bir terapötik rejimin seçilmesine ek olarak, hasta eğitiminin ve uygun deri bakımının da entegrasyonunu gerektirir. Deri bakımı ve dermokozmetik ürünler ile ilgili uygulamaların anlatılmasının ve uygun ürünlerin tedaviye eklenmesinin, hastaların farmakolojik tedaviye uyumunu artırdığı ve tedavi sonuçlarını iyileştirdiği gösterilmiştir'.

$A V^{\prime}$ de çeşitli sebeplerle derinin bariyer fonksiyonu bozulur. $A V^{\prime}$ de azalmış stratum korneum hidrasyonu ve bozulmuş stratum korneum interselüler lipid membranının göstergesi olarak azalmış serbest sfingozin ve azalmış total seramid miktarı gösterilmiştir. Ayrıca çeşitli farmakolojik tedaviler de stratum korneumun bütünlüğünü ve fonksiyonunu değiştirirler. Örneğin; benzoil peroksit (BPO) transepidermal su kaybını (TESK) artırarak, retinoidlerde deskuamasyonu artırıp stratum korneumu incelterek bariyer fonksiyonunu bozarlar. AV'de bu sebeplerle bozulmuş bariyer fonksiyonunun, uygun deri bakımı önerileri ve dermokozmetik ürünler ile desteklenmesi gerekmektedir ${ }^{1-3}$.

Akne hastalarında kanıta dayalı deri bakımı önerileri; derinin uygun şekilde temizlenmesi, nemlendirilmesi, güneş koruyucu kullanılması ve uygun makyaj ürünlerinin seçilmesi başlıkları altında ele alınacaktır.

Yazıșma Adresi/Address for Correspondence: Doç Dr. Illknur Balta

Ankara Eğitim ve Araştırma Hastanesi, Deri ve Zührevi Hastallklar Kliniği, Ankara, Türkiye

E-posta: drilknurderm@yahoo.com ORCID: orcid.org/0000-0002-0909-589X

(c) Telif Hakkı 2020 Deri ve Zührevi Hastalıklar Derneği

Türkderm - Türk Deri Hastalıkları ve Frengi Arșivi, Galenos Yayınevi tarafından basılmıștır. 


\section{Temizleme}

-Akneye yatkın kişilerde deri temizlenmesindekiamaç, deriyi kurutmadan ve irrite etmeden deri yüzeyindeki ter, kir, sebum, mikroorganizmalar ve eksfoliye olmuş keratinositleri uzaklaştırmaktır ${ }^{2,4}$.

Uygun bir temizleyici;

- Deriyi nazikçe temizler ve topikal tedavi için hazırlar.

- Derinin irritasyonunu ve dehidratasyonunu önler.

- Deri bariyer hasarını en aza indirger veya düzeltir.

- Komedogenezi engeller.

- Deri pH'sini sürdürür.

- P. acnes kolonizasyonunu azaltır.

- Temizleme sıklığı ideal olarak günde iki kez olmalı, ovalama ve fırçalama gibi agresif temizlemeden kaçınılmalıdır. Agresif temizleme deri pH'sini bozar ve deterjana bağlı akneye neden olur ${ }^{2-4}$.

Akne için kullanılan piyasadaki deri temizleyicileri:

- Kalıp temizleyiciler

- Likit temizleyiciler

- Antiseptikler

- Alfa-hidroksi asit içeren temizleyiciler

- BPO içeren temizleyiciler

- Salisilik asit içeren temizleyiciler şeklinde gruplandırılabilir".

- Kalıp temizleyiciler; bir alkali ve bir yağ asidinden oluşan, pH'si 9,5-10 olan gerçek sabunlar ve sentetik yüzey aktif madde içeren ve pH'si 5,5-7 (normal deri pH'sine benzer) olan sindet barlar olmak üzere iki formda piyasada bulunurlar.

- Gerçek sabunlar, deri pH'sini artırmak, bariyer fonksiyon geçirgenliğini azaltmak, bakteriyel florayı değiştirmek ve deriyi kurutmak suretiyle eritem, irritasyon ve foliküler oklüzyona neden olurlar ve ideal bir temizleyici olarak kabul edilmezler. Ayrıca bir çalışmada akneli hastalarda, gerçek sabun kullanarak yapılan deri temizliğinin enflamatuvar lezyon sayısını artırdığı gösterilmiştir ${ }^{5,6}$.

- Sindet barlar, derinin esansiyel lipid ve proteinlerini minimal etkileyerek, gerçek sabunlara göre, daha az irritasyon ve kuruluğa neden olurlar. Gerçek sabunlar, deri pH'sini artırırken; sindet sabunlar deri pH'sini değiştirmez veya azaltır. Bu nedenle akne hastalarında, deri temizliği için gerçek sabunlar yerine sindet sabunlar önerilmelidir 2,3,6.

- Likit temizleyiciler, bileşimlerindeki yüzey aktif emülsifiyerler ile derideki kir, sebum, bakteri ve korneositleri uzaklaştıran ajanlardır. Yapılan aktif madde olarak sodyum açil glutamat, sodyum lauret karboksilat ve alkil karboksilat içeren temizleyicilerin akne şiddetini azaltmada faydalı bulunmuştur ${ }^{6,7}$. Ancak daha geniş çalışmalara ihtiyaç bulunmaktadır.

- Antiseptik temizleyiciler, AV'de, P. acnes kolonizasyonunu azaltarak, hastalık şiddetinde iyileşme sağlamak amacıyla kullanılır. Literatürde AV için çalışılmış antiseptikler, heksaklorofen, klorheksidin ve povidoniyottur ${ }^{8-10}$. Ancak hasta merkezli kanıtların azlığı ve deri irritasyonu gibi yan etkileri sebebiyle AV tedavisinde, antiseptikler tavsiye edilmemektedir².

- BPO içeren temizleyiciler hafif-orta AV tedavisinin temelini oluşturur ${ }^{4,11,12}$. BP içeren temizleyiciler, diğer formülasyonlara göre irritasyon ve giysileri beyazlatma gibi yan etkiler açısından daha iyi tolere edilebilirler. $P$. acnes koloni sayısında anlamlı azalma ve akne şiddetinde iyileşme olduğu bildirilmiştir ${ }^{12,13}$. Hafif-orta akne tedavisinde, monoterapi olarak da önerilebilir².

- Salisilik asit içeren temizleyiciler stratum korneumdaki interselüler yüzey lipitleri çözündürerek komedonları açar. Literatürde BP içeren temizleyicilere göre daha iyi sonuçlar elde edilen çalışmalar bulunmaktadır ${ }^{14,15}$

- Alfa-hidroksi asit (glikolat ve laktat vb.) içeren temizleyiciler bazal korneosit kohezyonunu azaltarak deskuamasyonu sağlamak ve foliküler oklüzyonu açarak etki eder ${ }^{16}$.

Bu temizleme önerileri dışında piyasada tonik, sıkılaştırıcı, temizleyici krem, maske ve peeling ürünleri bulunmaktadır.

- Tonik ve sıkılaştırıcılar: Derideki yağın temizlenmesi, temizleyici bir ürün sonrası kalan sebum ve kir artığını uzaklaştırmak amacıyla kullanılırlar. Alkol içeriği \%20'den az olmalıdır. AV hastalarında alkol içeriği yüksek toniklerin kullanılması, folikül ağızlarını sıkılaştırarak komedon oluşumuna neden olabilir.

- Temizlik maskeleri: Deri yüzeyindeki lipidleri absorbe ederek, cildin sıkılaşması ve gözeneklerin derinlemesine temizlenmesini sağlarlar. Balmumu, vinil ya da kauçuk bazlı, hidrokolloid veya killi olmak üzere değişik maddelerle hazırlanırlar. Balmumu bazlı olanlar TESK'yi azalttıklarından kuru derilerde, killi maskeler yağlı derilerde daha uygundur. Bu maskeler yüze elle uygulandıktan sonra 10-30 dakika, deri yüzeyinde kaldıktan sonra, temizleyici bir ürünle yıkanarak çıkartıırlar.

- Eksfolyant temizleyiciler: Peeling yaparak etki eden temizleyicilerdir. Stratum korneumun deskuamasyonunu sağlayarak, derinin tazelenmesi ve incelmesini sağlarlar. Salisilik asit içeren eksfolyantlar, komedon oluşumunu engelleyerek, akne tedavisine yardımcı olurlar ${ }^{17}$.

\section{Nasıl önerelim:}

- Gerçek sabunlar, deri pH'sini artırarak bakteriyel florayı değiştirdiği ve deriyi kuruttuğu için AV tedavisinde tercih edilmezler. - Sindet sabunlar ve yağ içermeyen likit temizleyiciler AV hastalarında ideal temizleyicilerdir.

- AV'li hastalar için günde iki kez, uygun temizleyici ile deri temizliği yeterli ve uygundur.

\section{Nemlendirme}

- Akne tedavisinde kullanılan topikal (BPO, retinoidler, salisilik asit vb.) ve oral (izotretinoin) tedavilerinin, deri üzerinde irritasyon, kuruluk ve yanma gibi yan etkilerini azaltmak ve tedaviye uyumluluğu devam ettirmek için kullanılırlar. Ayrıca akne tedavilerinde kullanılan bu tedaviler stratum korneumun bariyer yapısını bozarak TESK'yi artırır ve enflamasyona sebep olur ${ }^{4,18}$.

- İdeal bir nemlendirici, nonkomedojenik, nonirritan ve hipoalerjenik olmalıdır.

- Nemlendiriciler içeriklerindeki üç temel ajan ile TESK'yi azaltırlar. Nem çeken ajanlar tek başına (örneğin gliserin vb.) kullanıldıklarında TESK'yi artıırken, oklüzif ajanla kombine edildiklerinde TESK'yi azaltırlar. Nemlendiriciler içinde en sık bulunan maddeler, özellikleri ile Tablo 1'de belirtilmiştir ${ }^{18}$

\section{Nasıl önerelim:}

- Su bazlı ve yağsız bir ürün (örneğin güneş koruyucu içeren bir nemlendirici), günde bir kez sabahları sürülebilir (hasta derinin özellikleri değerlendirilerek sıklık artırılabilir).

- Topikal akne tedavilerinin kuruluk ve yanma etkilerini azaltmak için, diğer topikal ajanlardan önce sürülmelidir.

\section{Diğer dermokozmetikler}

- Anormal sebum üretimini hedef alan ajanlar: Dermokozmetiklerdeki birkaç aktif içerik, sebosüpresif fonksiyon sağlayarak bu faktörü 


\begin{tabular}{|c|c|}
\hline Dimetikon, siklometikon & İyi bir oklüzif ve emolyent \\
\hline Gliserin & $\begin{array}{l}\text { Stratum korneum hidrasyonu için } \\
\text { en etkili }\end{array}$ \\
\hline Lanolin & $\begin{array}{l}\text { Alerjik kontakt dermatit riski } \\
\text { sebebiyle temkinli olunmalı }\end{array}$ \\
\hline Mineral yağlar & $\begin{array}{l}\text { Komedojenik olabilir-bileşendeki } \\
\text { derecesi önemli }\end{array}$ \\
\hline $\begin{array}{l}\text { Hyaluronik asit ve sodyum } \\
\text { pirolidon karboksilik asit }\end{array}$ & $\begin{array}{l}\text { Gliserine bağlı katı-yapışık hissi } \\
\text { ortadan kaldııılar. }\end{array}$ \\
\hline Botanik ekstreler & $\begin{array}{l}\text { Anti-enflamatuvar özellikleri ile } \\
\text { kullaniırlar. }\end{array}$ \\
\hline Çinko & $\begin{array}{l}\text { Anti-enflamatuvar ve yara iyileştirici } \\
\text { etkisi ile kullanılır. }\end{array}$ \\
\hline
\end{tabular}

hedef almaktadırlar. Son zamanlarda antioksidan ajanların [fulleren, epigallokatektin-3-gallat (epigallokateşin gallat; yeşil çaydaki majör polifenol) ve vitamin C] bu konudaki rolü öne çıkmaktadır ${ }^{19-21}$. Topikal nikotinamid de anti-enflamatuvar etkilerinin yanı sıra sebosüpresif etkisiyle bu alanda sık kullanılan ajanlardandır22.

- Anormal keratinizasyonu hedef alan ajanlar: Retinaldehit, retinol, alfa-hidroksi asitler, beta-hidroksi asitler, poli-hidroksi asitler ve linoleik asit gibi topikal komedolitikler, dermokozmetik ürünlerin içine düşük konsantrasyonlarda eklenirler. Enflamasyonu tetikleyen, pilosebase bez duktuslarındaki hiperkeratinizasyonu ve mikrokomedo formasyonlarını hedef alarak etkili olurlar ${ }^{23}$

- P. acnes'yi hedef alan ajanlar: Laurik asit veya gliseril laurat gibi orta zincirli yağ asitlerinin $P$. acnes üzerindeki antimikrobiyal aktiviteleri in vitro olarak gösterilmiştir ${ }^{24,25}$. Retinaldehit ve çinkonun da $P$. acnes üzerinde antibakteriyel etkileri bulunmaktadır26,27.

- Son zamanlarda topikal probiyotiklerin de antibakteriyel proteinler ile bu alanda işe yaradığı gösterilmiştir. Topikal probiyotikler, $P$. acnes'yi azaltmalarının yanı sıra, derinin bariyer fonksiyonunun iyileşmesine de katkı sağlamaktadırlar. AV'de iki klinik araştırmada topikal Enterococcus fecalis ve Lactobacillus plantarum'nin etkileri araştırılmış ve enflamatuvar lezyonları azalttığı gösterilmiştir ${ }^{28}$.

- Sülfür, dermatolojide yıllardır antibakteriyel, antifungal ve korneolitik ajan olarak kullanılmaktadır. Özellikle sülfürlü maskeler, antibakteriyel ve korneolitik etkileri ile AV tedavisinde iyi bir cevap sağlar ${ }^{29}$.

\section{Güneşten korunma}

- Güneşten koruyucular, postenflamatuvar hiperpigmentasyonu olan veya postenflamatuvar hiperpigmentasyon riski yüksek olan akne hastalarında tavsiye edilir. Akne hastaları, kozmetik olarak daha iyi görünmelerinden dolayı, ultraviyole ışınlarını absorbe eden ajanları tercih ederler. Dispigmentasyon, AV tedavisinin yaygın bir sonucu olduğundan, güneş koruyucu ürünlerle birlikte, renk açıc (azeleik asit, hidrokinon vb.) ürünlerin de kullanılması iyi bir kozmetik sonuç sağlayacaktır ${ }^{1,4}$.

\section{Kozmetik kamuflaj}

- Kozmetik kamuflaj veya makyaj, kozmetik görünümü düzeltmek amacıyla, deri lezyonlarının gizlenmesini amaçlamaktadır. Yaşam kalitesini ve tıbbi tedaviye uyumluluklarını artırdığı gösterilmiştiı ${ }^{30}$. Söğüt kabuğu özü, vitamin B, C ve E içeren bir kompakt fondöten kremin AV lezyonlarını azalttığı gösterilmiştir ${ }^{31}$. Hastalara mümkünse akne lezyonların azaltan aktif içerikleri olan, komedojenik ve alerjik olmayan, kolay uygulanabilir uygun kozmetik ürünler tavsiye edilmelidir.

- Akneli hastalarda, yağ içermeyen mat/yarı mat fondötenler tercih edilebilir. Yağı fondötenler kadar etkili kapatıclık sağlamasalar da akneyi şiddetlendirme riskleri oldukça düşüktür.

- Pudralar yağsız olması ve derideki fazla sebumu absorbe ederek parlak görünümü azaltması nedeniyle akne hastaları tarafından oldukça sık tercih edilirler. Gevşek, transparan pudralar, kompakt pudralara oranla daha az yağlı olup komedojenite riskleri düşüktür ${ }^{17}$.

\section{Nasıl önerelim:}

- Kozmetik olarak daha uygun bir görünüm sağlaması sebebiyle, su bazlı ultraviyole absorbe eden kimyasal ajanlar içeren güneş koruyucular önerilebilir. - Dispigmentasyon riski yüksek olan hastalar için geniş spektrumlu güneş koruyucular seçilmelidir.

- Akneli hastalar, önce yağsız bir nemlendirici, hemen arkasından mat/yarı mat bir fondöten, en son olarak da gevşek, transparan bir pudra uygulayarak etkili ve uzun süreli bir kozmetik kamuflaj sağlayabilirler.

\section{Kaynaklar}

1. Zip C: The role of skin care in optimizing treatment of acne and rosacea Skin Therapy Lett 2017;22:5-7.

2. Stringer T, Nagler A, Orlow SJ, Oza VS: Clinical evidence for washing and cleansers in acne vulgaris: a systematic review. J Dermatolog Treat 2018;29:688-93

3. Levin J: The relationship of proper skin cleansing to pathophysiology, clinical benefits, and the concomitant use of prescription topical therapies in patients with acne vulgaris. Dermatol Clin 2016;34:133-45.

4. Goh CL, Noppakun N, Micali G, et al: Meeting the challenges of acne treatment in Asian Patients: A review of the role of dermocosmetics as adjunctive therapy. J Cutan Aesthet Surg 2016;9:85-92.

5. Ananthapadmanabhan KP, Moore DJ, Subramanyan K, Misra M, Meyer F: Cleansing without compromise: the impact of cleansers on the skin barrier and the technology of mild cleansing. Dermatol Ther 2004;17:16-25.

6. Isoda K, Seki T, Inoue $Y$, et al: Efficacy of the combined use of a facial cleanser and moisturizers for the care of mild acne patients with sensitive skin. J Dermatol 2015;42:181-8.

7. Isoda K, Takagi Y, Endo K, et al: Effects of washing of the face with a mild facial cleanser formulated with sodium laureth carboxylate and alkyl carboxylates on acne in Japanese adult males. Skin Res Technol 2015;21:247-53.

8. Lewis RJ, Martin R, Tkach J: Effectiveness of hexachlorophene and surgical sponges in the treatment of acne. Curr Ther Res Clin Exp 1972;14:270-6.

9. Stoughton RB, Leyden JJ: Efficacy of 4.percent chlorhexidine gluconate skin cleanser in the treatment of acne vulgaris. Cutis 1987;39:551-3.

10. Khan SA: Hibiscrub in acne. Br Med J 1975;4:346

11. Burkhart CG, Scheinfeld NS: Benzoyl peroxide skin washes: basis, logic, effectiveness, and tolerance. Skinmed 2005;4:370.

12. Leyden JJ, Del JR: The effect of benzoyl peroxide $9.8 \%$ emollient foam on reduction of Propionibacterium acnes on the back using a short contact therapy approach. J Drugs Dermatol 2012;11:830-3.

13. Zeichner JA, Wong V, Linkner RV, Haddican M: Efficacy and safety of tretinoin $0.025 \% /$ clindamycin phosphate $1.2 \%$ gel in combination with benzoyl peroxide $6 \%$ cleansing cloths for the treatment of facial acne vulgaris. J Drugs Dermatol 2013;12:277-82.

14. Arif T: Salicylic acid as a peeling agent: a comprehensive review. Clin Cosmet Investig Dermatol 2015;8:455-61. 
15. Chen T, Herndon J, Stephens T, Appa Y: Rapid and lasting acne reduction by an oil free cleanser containing salicylic acid microgel complex. J Am Acad Dermatol 2007;56:AB20.

16. Abels $C$, Reich $H$, Knie U, Werdier D, Lemmnitz G: Significant improvement in mild acne following a twice daily application for 6 weeks of an acidic cleansing product (pH 4). J Cosmet Dermatol 2014;13:103-8.

17. Sarıcaoğlu H, Karadoğan SK: Aknede Deri Bakımı ve Kozmetik Seçimi. Turkiye Klinikleri J Int Med Sci 2006;2:55-60.

18. Chularojanamontri L, Tuchinda P, Kulthanan K, Pongparit K: Moisturizers for acne: what are their constituents? J Clin Aesthet Dermatol 2014;7:36-44.

19. Inui $\mathrm{S}$, Aoshima $\mathrm{H}$, Nishiyama $\mathrm{A}$, Itami $\mathrm{S}$ : Improvement of acne vulgaris by topical fullerene application: unique impact on skin care. Nanomedicine 2011;7:238-41.

20. Yoon JY, Kwon HH, Min SU, Thiboutot DM, Suh DH: Epigallocatechin-3gallate improves acne in humans by modulating intracellular molecular targets and inhibiting P. acnes. J Invest Dermatol 2013;133:429-40.

21. Woolery-Lloyd H, Baumann L, Ikeno H: Sodium L-ascorbyl-2-phosphate $5 \%$ lotion for the treatment of acne vulgaris: a randomized, double-blind, controlled trial. J Cosmet Dermatol 2010;9:22-7.

22. Biedermann K, Lammers K, Mrowczynski E, et al: Regulation of sebum production by nicotinamide. New Orleans: 60th Annual Meeting of the American Academy of Dermatology: 2002.

23. Green BA, Ruey JY, Van Scott EJ: Clinical and cosmeceutical uses of hydroxyacids. Clin Dermatol 2009;27:495-501.
24. Higaki S: Lipase inhibitors for the treatment of acne. J Mol Catal B Enzym 2003;22:377-84

25. Yang D, Pornpattananangkul D, Nakatsuji T, et al: The antimicrobial activity of liposomal lauric acids against Propionibacterium acnes. Biomaterials 2009;30:6035-40.

26. Pechere M, Germanier L, Siegenthaler G, Saurat J H: The antibacterial activity of topical retinoids: the case of retinaldehyde. Dermatology 2002;205:1538.

27. Dreno B, Foulc P, Reynaud A, Dominique Moyse, Habert H, Richet H: Effect of zinc gluconate on propionibacterium acnes resistance to erythromycin in patients with inflammatory acne: in vitro and in vivo study. Eur J Dermatol 2005;15:152-5.

28. Kober M, Bowe WP: The effect of probiotics on immune regulation, acne, and photoaging. Int J Womens Dermatol 2015;1:85-9.

29. Toombs EL: Cosmetics in the treatment of acne vulgaris. Dermatol Clin 2005;23:575-81.

30. Levy LL, Emer JJ: Emotional benefit of cosmetic camouflage in the treatment of facial skin conditions: personal experience and review. Clin Cosmet Investig Dermatol 2012;5:173-82.

31. Monfrecola G, Cacciapuoti S, Capasso C, Delfino M, Fabbrocini G: Tolerability and camouflaging effect of corrective makeup for acne: results of a clinical study of a novel face compact cream. Clin Cosmet Investig Dermatol 2016;9:307-13. 